\section{Re-launch of African Journals OnLine (AJOL), http://www.ajol.info}

The International Network for Scientific Publications (INASP) launched AJOL in 1998 with only 10 journals. By January 2004 it had over 175 African journals covering most subject areas. It is now being re-launched on its own website that continues to provide free access to tables of contents and abstracts for all titles - but also provides a number of additional facilities. AJOL offers a document delivery service, and full (improved) searching and browsing facilities, as well as a new Email alert function. The service remains free to both users and participating journals (with charges only for document delivery requests from outside developing countries).

Journals included in AJOL are scholarly in content with peer reviewed articles, and publish a mixture of pure and applied research as well as review papers. Journals included cover Agricultural sciences and resource management; Arts, culture, language and literature; Health; Science and technology; and Social sciences. An evaluation of the AJOL senvice undertaken at the end of 2002 showed that participating journals benefit from the international visibility, with more international submissions and citations, and that users value access to African research that they have been unable to locate from other sources. Use of the service has more than doubled in the past few years (almost 4000 people registered during 2003) and the demand for document delivery tripled (reaching over 650 articles during 2003). The evaluation highlighted a need to update the website, to make it easier to use with an emphasis on improved searching and retrieval of articles.

In response to the evaluation, the new website now offers a greatly improved and more sophisticated search system and email alerting to identify new issues. Journals can also manage their own content online, giving them more control over their own work. We look forward to more users, an increase in demand for document delivery and increased worldwide visibility for African published research.

Please visit the new site http://www.ajol.info - and sign up for email alerts to any journals of interest.

We also welcome new journals onto the service - please contact INASP for further information: ajol@ inasp.info or visit our website http://www.inasp.info. You may also contact Mrs Pippa Smart Head of Publications, Publishing Initiatives and Publishing Training, INASP (International Network for the Availability of Scientific Publications), PO Box 516, Oxford OX1 1WG, UK, Tel: +44 (0)1865 249909 Fax: +44 (0)1865 251060 .

\title{
Awards and Fellowships
}

\section{U.S. Fulbright scholar award information and application materials for 2005-2006 are now available!}

Awards are to over 25 Sub-Saharan African countries, including: Benin, Botswana, Burkina Faso, Cameroon, Chad, Cote d'Ivoire, Democratic Republic of the Congo, Eritrea, Ethiopia, Ghana, Guinea, Kenya, Madagascar, Malawi, Mali, Mauritius, Mozambique, Namibia, Niger, Nigeria, Rwanda, Senegal, South Africa, Swaziland, Tanzania, Uganda, Zambia and Zimbabwe.

Grants are available for scholarly research in all fields including AIDS and AIDS-related research. Combined lecturing and research awards are also available, some in specific fields; most in all disciplines offered at the host institution.

Please visit www.cies.org $<$ <ttp://www.cies.org> under "Traditional
Scholar Program" for award descriptions, application forms, instructions and guidelines. U.S. citizenship required and a Ph.D. or equivalent professional/terminal degree.

For more information contact: Debra Egan, Tel: 202-686-6230, email degan@cies.iie.org or Msia Clark, Tel. 202-686-4027, email mclark@cies.ile.org.

\section{The United States}

\section{Institute of Peace}

The United States Institute of Peace invites applications for the 2005-2006 Senior Fellowship competition in the Jennings Randolph Program for International Peace. The United States Institute of Peace is an independent, nonpartisan institution created by Congress to strengthen the nation's capacity to promote the peaceful resolution of international conflict. Twelve to fifteen fellowships are awarded annu- ally to scholars and practitioners from a variety of professions, including college and university faculty, journalists, diplomats, writers, educators, military officers, international negotiators, NGO professionals, and lawyers. The Institute funds projects related to preventive diplomacy, ethnic and regional conflicts, peacekeeping and peace operations, peace settlements, democratization and the rule of law, cross-cultural negotiations, nonviolent social movements, U.S. foreign policy in the 21st century, and related topics. This year the Institute is especially interested in topics addressing problems of the Muslim world, post-war reconstruction and reconciliation in Iraq and responses to terrorism and political violence. Projects which demonstrate relevance to current policy debates will be highly competitive. Fellows reside at the Institute in Washington, D.C., for a period of up to ten months to conduct research on their projects, consult with 